\title{
CONF- $940416--33$
}

Note: This is a preprint of a paper submitted for publication. Contents of this paper should not be quoted or referred to without permission of the author(s).

Presented at 96th Annual Meeting of the American Ceramic Society, Indianapolis, Indiana, April 24-28, 1994 and to be published in meeting proceedings: Ceramic Transaction: Ceramic Components, published by the American Ceramic Society

\section{POLARIZATION RELAXATION IN ZINC OXIDE VARISTORS FROM $77 \mathrm{~K}$ to $450 \mathrm{~K}^{*}$}

R. W. Major, A. E. Werner, and C. B. Wilson

Department of Physics, University of Richmond

Richmond, Virginia 23173

F. A. Modine

Solid State Division, Oak Ridge National Laboratory

Oak Ridge, Tennessee 37831-6030

*This research was sponsored by the Division of Materials Sciences, U.S. Department of Energy, under contract DE-AC05-84OR21400 with Martin Marietta Energy Systems, Inc.

"The submitted manuscript has been authored
by a contractor of the U.S. Government under
contract No. DE-ACO5-84OR21400.
Accordingly, the U.S. Government retains a
nonexclusive, royaliy-free license to publish or
reproduce the published form of this
contribution, or allow others to do so, for U.S.
Government purposes."

SOLID STATE DIVISION

OAK RIDGE NATIONAL LABORATORY

Managed by

MARTIN MARIETTA ENERGY SYSTEMS, INC.

under

Contract No. DE-AC05-84OR21400

with the

U.S. DEPARTMENT OF ENERGY

Oak Ridge, Tennessee

October 1994 
POLARIZATION RELAXATION IN ZINC OXIDE VARISTORS FROM $77 \mathrm{~K}$ TO $450 \mathrm{~K}$

R. W. Major, A. E. Werner and C. B.Wilson

Department of Physics

University of Richmond

Virginia 23173

F. A. Modine

Solid State Division

Oak Ridge National Laboratory

Oak Ridge, Tennessee 37831-6030

\section{ABSTRACT}

The time and temperature dependences of polarization currents are investigated to higher temperatures and with greater temperature resolution than has been reported previously for zinc oxide varistors. Arrhenius plots yield thermal activation energies near 140 and $8 \mathrm{meV}$, which are in reasonable agreement with values reported recently, as well as an additional thermally activated level at 0.66 $\mathrm{eV}$, which emerges in the extension of the measurements to $\mathrm{T}>300 \mathrm{~K}$. Conductance data in this higher temperature range for the same samples yield the nearly identical energy of $0.68 \mathrm{eV}$ for the intergranular (Schottky) barrier height. The temperature dependence of the exponent $m$ in the power - law expression for the current - time dependence $\mathrm{I}=\mathrm{I}_{0} \mathrm{t}-\mathrm{m}$ was carefully examined and found to change twice from 0.5 to 1.0 . The non - monotonic behavior of $\mathrm{m}$ with temperature is interpreted as due to resolution of the polarization currents from two different traps each of which makes the transition from diffusive to dispersive transport as temperature is lowered rather than, for example, a complicated distribution of relaxation times.

\section{DISCLAIMER}

This report was prepared as an account of work sponsored by an agency of the United States Government. Neither the United States Government nor any agency thereof, nor any of their employees, makes any warranty, express or implied, or assumes any legal liability or responsibility for the accuracy, completeness, or usefulness of any information, apparatus, product, or process disclosed, or represents that its use would not infringe privately owned rights. Reference herein to any specific commercial product, process, or service by trade name, trademark, manufacturer, or otherwise does not necessarily constitute or imply its endorsement, recommendation, or favoring by the United States Government or any agency thereof. The views and opinions of authors expressed herein do not necessarily state or reflect those of the United States Government or any agency thereof. 


\section{DISCLAIMER}

Portions of this document may be illegible in electronic image products. Images are produced from the best available original document. 


\section{INTRODUCTION}

The literature of dielectric behavior is rich in examples of non-Debye response, and in particular with varistor characteristics as instances of such non-exponential relaxations.1-5 Electrical measurements in the time domain are useful complements to the more abundant data available in the frequency regime; the Fourier transform relates the current $I(t)=I_{\alpha} / t^{m}$ to the a.c. admittance $Y(\omega)$ :

$$
Y(\omega)=\left(I_{0} / V_{0}\right) \Gamma(1-m)(j \omega)^{m}
$$

where $V_{0}$ is the magnitude of the potential step and $\Gamma(1-m)$ denotes the gamma function with its argument. More generally, the Havriliak - Negami function 6

$$
Y(\omega)=I(\omega) / V(\omega) \sim j \omega\left[1+(j \omega \tau)^{1-\alpha}\right]-\beta
$$

in turn simplifies to the Debye $(\alpha=0, \beta=1)$, the Cole - Cole $(\beta=1)$, or the Davidson - Cole $(\alpha=0)$ descriptions. It has been noted that the exponent $\mathrm{m}$ in equation (1) may itself be a function of temperature, but no systematic examination of this dependence has been published.

It has been widely observed that dielectrics generally and metal oxide varistors specifically display a time-dependent discharge current $I=I_{0} t-m$ following the removal of a charging potential. The same empirical description fits the charging process equally well, although a steady -state current is also induced when the potential is applied. Here $I_{0}$ is constant only at a given temperature and for a particular specimen, and $\mathrm{m}$ is usually described as being slightly less than one, typical values ranging from 0.5 to 1.0 .7 Jonscher points out that such power-law dependence is nearly universal in dielectrics, 8 and its validity has been confirmed over at least twelve orders of magnitude for $\mathrm{ZnO}$ varistors. 9 For limited ranges of temperature it is also evident that the temperature dependence of these currents at a fixed time after removal of the applied field is of the form $I_{0}=I_{0 T} e^{-E / k T}$, where $\mathrm{k}$ is Boltzman's constant and $\mathrm{E}$ is an activation energy. The discharge current between $77 \mathrm{~K}$ and $300 \mathrm{~K}$ is well described as a sum of two such contributions with $E_{1}=160 \mathrm{meV}$ and $E_{2}=10 \mathrm{meV} 9$ and a series of deeper 
trapping levels have been reported for $\mathrm{ZnO}$ varistors from 0.22 to $0.97 \mathrm{eV}$, using deep level transient spectroscopy (DLTS) and ac admittance spectroscopy. 10 These have not appeared in thermal spectra of polarization currents up to $300 \mathrm{~K}$, but it has been anticipated that similar measurements at higher temperatures might reveal such deep levels if they are present in sufficient concentration. 9

\section{EXPERIMENTAL PROCEDURES}

All measurements were made on commercial RCA $2 \mathrm{~V} 130$ medium - voltage $\mathrm{ZnO}$ varistors of the type formerly designated GE V130L20. Transient discharge currents were measured following removal of a polarizing electric field, essentially as described by Philipp and Levinson. 7 A Keithley model 614 electrometer with $10^{-14}$ Amp sensitivity operated in a continuous mode, furnishing current data to a separate Keithley model 175 data logger. Temperature was maintained by cooling the sample, immersed in mineral oil, with a surrounding bath of liquid refrigerant isolated from the sample container by an air gap. A resistance wire wound directly on the Pyrex sample container served as a heat source to raise the temperature as far above that of the refrigerant as was desired.

Because offset currents are nearly impossible to eliminate entirely and can seriously distort dc measurements, all data used are averages of two sets of measurements made with opposing polarities of the applied field. The charging voltage was $50 \mathrm{~V}$, small enough to avoid serious non-linearities associated with the 200 Volt breakdown threshold but sufficient to yield currents typically above 10-12 Amp (Figure 1). The temperature dependence of the slope $m$ of $\ln (\mathrm{I})$ vs. $\ln (t)$ is illustrated by Figure 2. Finally we note that at low temperatures, the charging currents do not saturate for many minutes. At $77 \mathrm{~K}$ and 40 Volts, $10^{3}$ seconds are required to reach a steady charging current .

Conductance $(G=1 / R)$ was obtained from steady state resistance measured with the same instruments. In the resistance mode, the electrometer maintains a constant $0.1 \mathrm{nA}$ current in the sample. The heating rate used for $\mathrm{G}$ vs $\mathrm{T}$ measurements was not linear, ranging from $0.4 \mathrm{~K} / \mathrm{min}$ near room temperature to 
about $0.2 \mathrm{~K} / \mathrm{min}$ near $450 \mathrm{~K}$.

\section{RESULTS}

Arrhenius plots of discharge currents after 2,20, and 100 seconds of discharge display two distinct linear regions at temperatures below $300 \mathrm{~K}$ which correspond to activation energies $E_{1}$ and $E_{2}$ of 140 and $8 \mathrm{meV}$ (Figure 3). These agree with the 160 and $10 \mathrm{meV}$ values reported previously for similar GE varistors of slightly larger physical dimensions. 9 We do not see the level near $0.36 \mathrm{eV}$ measured by many others using a variety of methods; this may be a consequence of the essentially 'detuned' nature of time domain measurements of polarization currents. Above $350 \mathrm{~K}$, a new slope appears which is quite linear and corresponds to a barrier height $E_{3}=0.66 \mathrm{eV}$. In the $290-350 \mathrm{~K}$ range, however, a plateau or possible local maximum seen in Figure 3 complicates efforts to resolve the slopes of neighboring linear segments, so this value reflects a minimum slope and therefore a minimum value for $E_{3}$. Conductance data in the $290-450 \mathrm{~K}$ range fits the expression $\mathrm{G}(\mathrm{T})=\mathrm{G}_{\mathrm{o}} \mathrm{e}-\mathrm{E}_{3} / \mathrm{kT}$ over at least 3 orders of magnitude, with $E_{3}=0.68 \mathrm{eV}$ (Figure 4).

The plateau region in Figure 3 may simply represent current saturation as a consequence of limited charge population in the 140-160 meV trapping level. An alternative explanation is that at least two traps contribute, as evidenced by the anamolous increase in $\mathrm{m}$ with temperature which has not been previously reported. This change in $\mathrm{m}$ decreases the slope of the Arrhenius plot, creating the plateau. That the plateau narrows at earlier times is consistent with this explanation; the decrease in slope is proportional to $\ln (t)$. The remaining data of Figure 3 show a strongly activated current in the $400 \mathrm{~K}$ to $450 \mathrm{~K}$ temperature range, yielding the activation energy $0.66 \mathrm{eV}$ already mentioned. Steady - state conductance data in the same temperature range indicate a thermal activation energy of $0.68 \mathrm{eV}$ (Figure 4).

As seen in Figure 5 , the slope $m$ of $\ln (1)$ vs. $\ln (t)$ at eighteen temperatures varies between values that equal, but do not exceed unity as an upper bound, or one-half as lower bound. The fact that $\mathrm{m}$ is temperature-dependent has been alluded to only occasionally in the literature, and rarely discussed further. A key 
reason has probably been the considerable investment of experimental time required to examine this in any detail. The frequent observations that $m$ has a magnitude somewhat less than unity are clearly inadequate, or at least insufficiently qualified. At two temperatures $(110 \mathrm{~K}, 330 \mathrm{~K})$ it is indistinguishable from 1 , and at two others $(230 \mathrm{~K}, 450 \mathrm{~K})$ equal or close to 0.5 for $\mathrm{ZnO}$ varistors. All intermediate values of $\mathrm{m}$ occur as well, and in a surprisingly repetitive fashion.

\section{DISCUSSION}

The thermal spectrum of discharge currents in $\mathrm{ZnO}$ varistors has structure which reveals an electronic trapping state at $0.66 \mathrm{eV}$, in addition to excitations recognized previously near $0.16 \mathrm{eV}$ and $10 \mathrm{meV} .18$ The latter is unlikely to be a trap, due to the low energy involved. It has, however been seen by others. The $10 \mathrm{meV}$ energy is likely the result of tunneling through the barrier, rather than thermal activation over the barrier. Support for this view is provided by calculations of Seager and Pike.12 In addition, there exists a continuous range of values for the slope $m$ in the universal expression for discharge current, $I=$ $\mathrm{I}_{0} \mathrm{t}^{-\mathrm{m}}(\mathrm{T})$. As well as being the low temperature limit, the value $\mathrm{m}=1$ also appears as a localized maximum at about $330 \mathrm{~K}$. Existing models for varistors do not accomodate this behavior. However, recent work by Lee et al is of considerable value in the interpretation of our results. 13 Their experiments in the frequency domain were performed throughout nearly the same temperature range on several ionically conducting crystals and glasses. In crystalline Gd - doped $\mathrm{CeO}_{2}$ they report values of $\mathrm{m}$ (designated ' $\mathrm{s}$ ' in their paper) which increase monotonically from 0.6 to 1.0 as temperature is reduced from $400 \mathrm{~K}$ to $77 \mathrm{~K}$. Plotted in Figure 5 are our data for $\mathrm{ZnO}$ varistors, showing more complex behavior. Clearly these disparate systems share aspects of the 'universal' behavior described by Jonscher; both display values of the power - law exponent which are close to unity at low temperatures, as well as high - temperature values that approach 0.5 . The high temperature regime in which $\mathrm{m} \sim 0.5$ has been interpreted by Lee as the "classical universal" region of Jonscher and coworkers, wherein the exponent is substantially less than one. Lee et al also verify that the Almond - West form of the ac conductivity, 


$$
\sigma(\omega)=\sigma(0)[1+(\omega \tau)]^{m}
$$

is valid, where $\sigma(0)$ is the dc conductivity, and $0<\mathrm{m}<1$. The physical significance of this, as concluded by Lee and supported by the present varistor data, is that the ac relaxation effect and the dc conductivity are closely coupled through ion - ion interactions in a hopping process. At much lower temperatures, after a transition through smoothly increasing values of $m$ the same workers find that $\mathrm{m}=1$ is actually reached, and not just approached, in simple systems with low defect concentrations. 13 They conclude that existing theoretical models are unsatisfactory, since most are based on a high and random degree of disorder inconsistent with the simple defect structure of the crystalline materials they examined. We note that $S c h e r$ et al. explain the transition from $m=0.5$ to $m=1$ in terms of a convergence of the moments of the distribution of transit times. 14 That is, this behavior results as a limit of a statistical distribution and no particular process need be assumed; Jonscher's universality is implicitly contained.

The distinctive feature of the $\mathrm{ZnO}$ varistor data shown in Figure 5 is the repeated appearance of dispersive behavior $(m=1)$ as the temperature is reduced, interspersed by thermal regions in which normal charge diffusion $(m=0.5)$ is evident. No evidence of such behavior appears in the work of Lee, all of whose crystalline as well as vitreous materials are characterized by an $m(T)$ which makes a single smooth transition from $\mathrm{m}=0.5$ to $\mathrm{m}=1$ over the same decreasing temperature range. Only the two traps near 0.14 and $0.66 \mathrm{eV}$ are well resolved in the polarization currents from our samples, though other traps must also contribute. The $0.14 \mathrm{eV}$ trap is a well - known bulk trap, and $0.66 \mathrm{eV}$ can be interpreted as an interface trap (Figure 6). This latter is consistent with Cordaro's single - junction range of values whose mean is $0.65+/-0.1 \mathrm{eV} .15$ There is also agreement with the state identified by Maeda, Meguro and Takato 16 and identified by them as a $\mathrm{Zn}: \mathrm{Bi}, \mathrm{Mn}$ interface state, and with the $0.6-0.7 \mathrm{eV}$ interface state reported by Gambino in $\mathrm{Bi}$ - doped $\mathrm{ZnO} .17$ Emtage calculates a barrier height of - $0.5-0.6 \mathrm{eV}$, using the assumption that the distinctive electrical behavior of $\mathrm{ZnO}$ varistors is associated with the insulating layers between the grains. 18 In addition Morris ${ }^{19}$, Eda 20 , Prudenziati21 and Alim 22 report comparable barrier heights of $0.53,0.8,0.7$, and $0.7 \mathrm{eV}$ respectively. The numerical mean of values from references $15-22$ is $0.65 \mathrm{eV}$, with an rms deviation of $0.09 \mathrm{eV}$. At 
higher temperatures this state dominates the transient discharge because there are many of them, and the $0.14 \mathrm{eV}$ level empties too quickly to be observed. As temperature drops, the current makes the transition from normal to dispersive transport, i.e. from $m=0.5$ to $m=1$. At still lower temperatures electrons are essentially frozen into the deeper $0.66 \mathrm{eV}$ levels and only the $0.14 \mathrm{eV}$ traps contribute. They, of course, make the same transition from normal to dispersive transport and once again $\mathrm{m}$ goes from 0.5 to 1 .

\section{CONCLUSIONS AND SUMMARY}

Two species of trap seem to be revealed by contributions at different temperatures, both making the same type of transition from normal to dispersive transport with decreasing temperature. Figure 6 illustrates our interpretation, portraying four key mechanisms: (1) over - barrier conduction, (2) emission from interface traps, (3) emission from bulk traps, and (4) tunneling from the interface through the barrier to the conduction band. Transient discharge currents have an activation energy corresponding to the depth of the trapping level as measured from the conduction band, while dc conductance measures the activation energy for current flow over the intergranular barrier, as measured from the Fermi level. Bulk traps fill and empty during charge and discharge of the varistor and have a low activation energy (e.g. $0.14 \mathrm{eV}$ ). Also electrons may tunnel from the interface.

At least in varistors, with their intergranular boundaries and impurities, it appears unlikely that any single mechanism such as a distribution of Debye - like relaxation times can adequately incorporate both the time and temperature dependence of depolarization currents. At the same time, varistor materials do exhibit 'universal' dielectric behavior to the degree that $\mathrm{m}=1$ at low temperatures, and $\mathrm{m} \sim 0.5$ at high temperature. We conclude that (1) there is an interface trap in excellent agreement with the barrier height near $0.66 \mathrm{eV}$ and that (2) the most complicated variation of $m(T)$ yet reported reflects a double, or repeated transition from normal to dispersive transport, in two distinct temperature ranges. The intermediate $\mathrm{m}$ - values often reported as falling between 0.5 and 1.0 arise from the fact that most measurents are performed at temperatures (e.g 295K) where neither characteristic dominates. 


\section{REFERENCES}

1. J. C. Simpson and J. F. Cordaro, J. Appl. Phys. 67, 6760 (1990)

2. Y. Shim and J. F. Cordaro, J. Appl. Phys. 64, 3994 (1988)

3. J. F. Cordaro, Y. Shim and J. E. May, J. Appl. Phys. 60, 4186 (1986)

4. K. Tsuda and K. Mukae, in High Tech Ceramics, edited by P. Vincanzini (Elsevier, Amsterdam, 1987); pp 1781 - 1790, Proceedings of 6th CIMTEC, Milan, Italy (1986)

5. M. A. Alim, J. Am. Ceram. Soc. 72, 28 (1989)

6. S. Havriliak and S. Negami, Polymer 8, 161 (1967)

7. H. Philipp and L. M. Levinson, J. Appl. Phys. 47, 3177 (1976)

8. A. K. Jonscher, Dielectric Relaxation In Solids, Chelsea Dielectrics, London, (1983)

9. F. A. Modine, R. W. Major, S. I. Choi, L. D. Bergman and M. N. Silver, J. Appl. Phys. 68, 339 (1990)

10. R. A. Winston and J. F. Cordaro, J. Appl. Phys. 68, 6495 (1990)

11. S-N. Bai and T-Y. Tseng, J. Appl. Phys. 74, 695 (1993)

12. C.H. Seager and G. E. Pike, Appl. Phys. Lett. 40, 471 (1982)

13. W. K. Lee, B. S. Lim, J. F. Liu and A. S. Nowick, Solid State Ionics 53-56, 831 (1992)

14. H. Scher, M. F. Shlesinger and J. T. Bendler, Physics Today, 26 (Jan. 1991)

15. H. Wang, W. Li and J. F. Cordaro, (to be published)

16. T. Maeda, S. Meguro and M. Takata, Jpn. J. Appl. Phys. 28, L714 (1989)

17. J. P. Gambino, W. D. Kingery, G. E. Pike, H. R. Philipp and L. M. Levinson, J. Appl. Phys. 61, 2571 (1987)

18. P. R. Emtage, J. Appl. Phys. 48, 4372 (1977) 
19. W. G. Morris, J. Vac. Sci. Tech. 13, No. 4, 926 (1976)

20. K. Eda, J. Appl. Phys. 49(5), 2964 (1978)

21. M. Prudenziati, A. Masoero and A. M. Rietto, J. Appl. Phys. 58, 345, (1985)

22. M. A. Alim, M. A. Seitz and R. W. Hirthe, J. Appl. Phys. 63, 2337 (1988) 


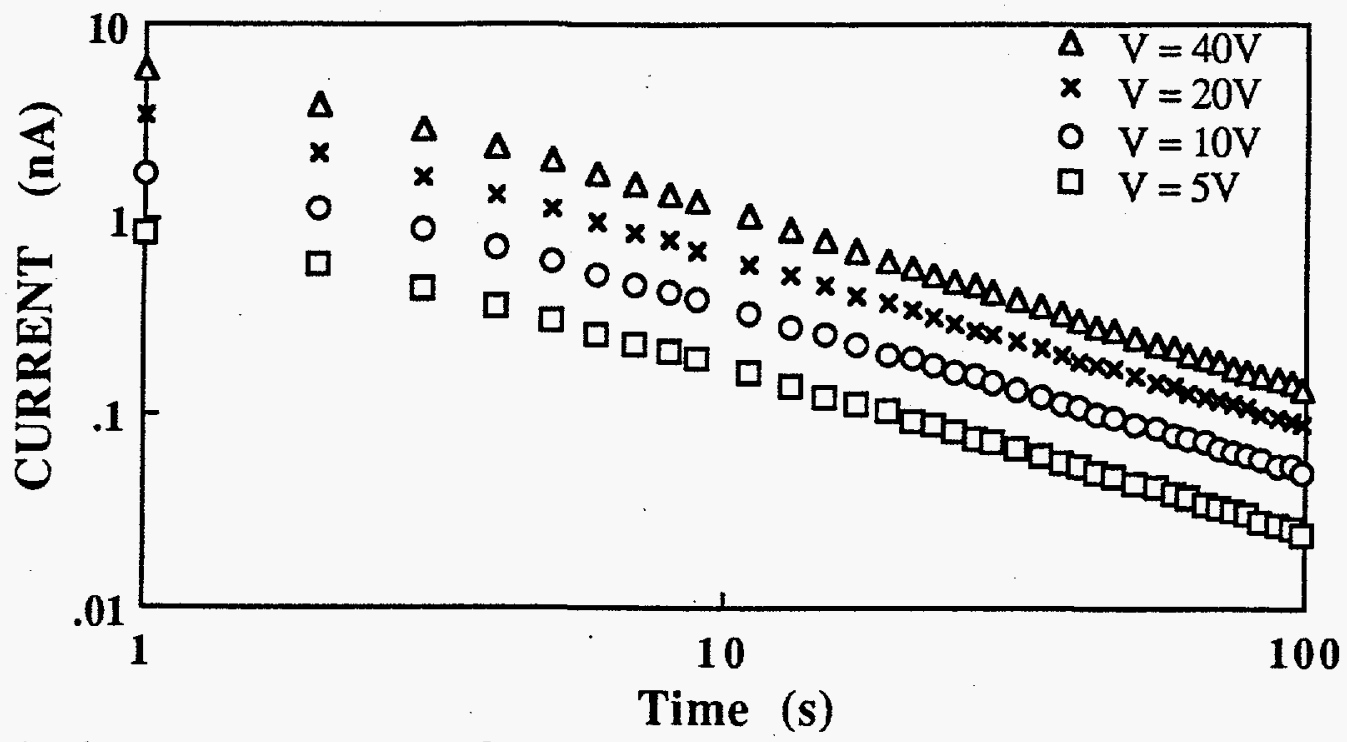

Fig.1. Discharge as a function of time at successively doubled potentials. All measurements taken at $295 \mathrm{~K}$.

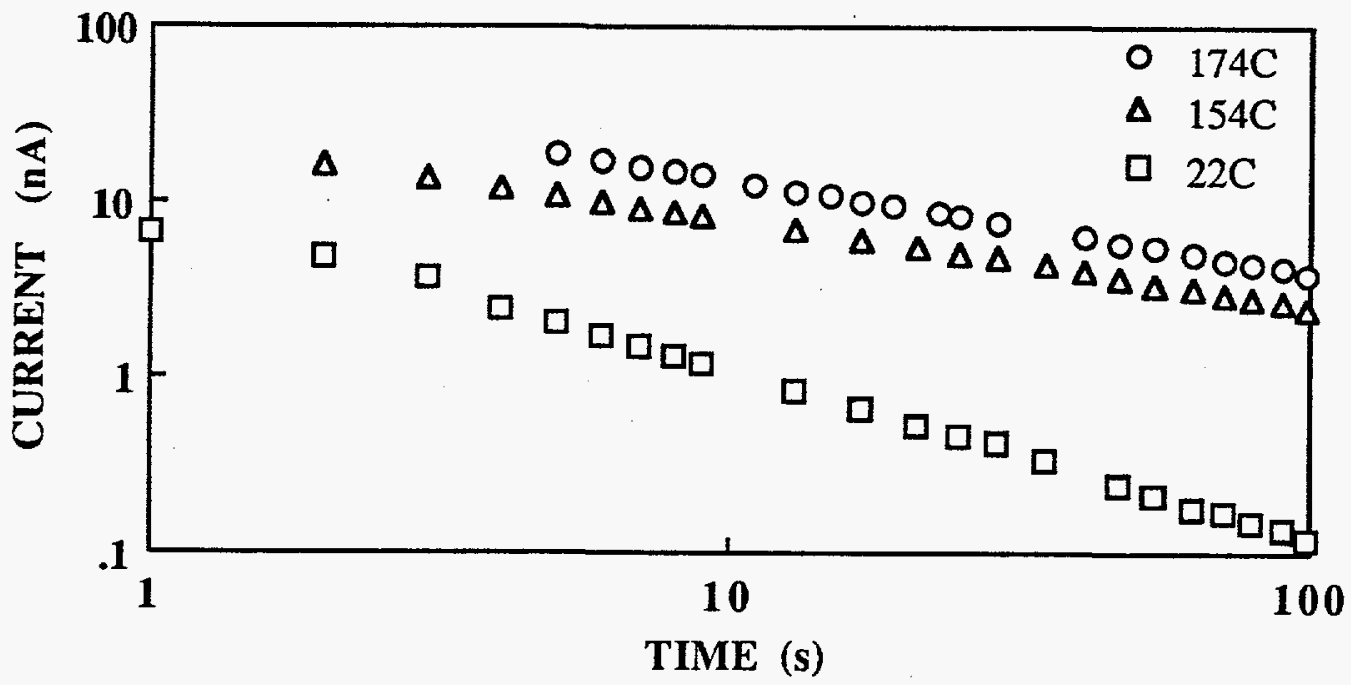

Fig. 2. Differing slopes of $\ln (I)$ vs $\ln (t)$ at three arbitrarily chosen temperatures. The charging potential is 50 Volts. 


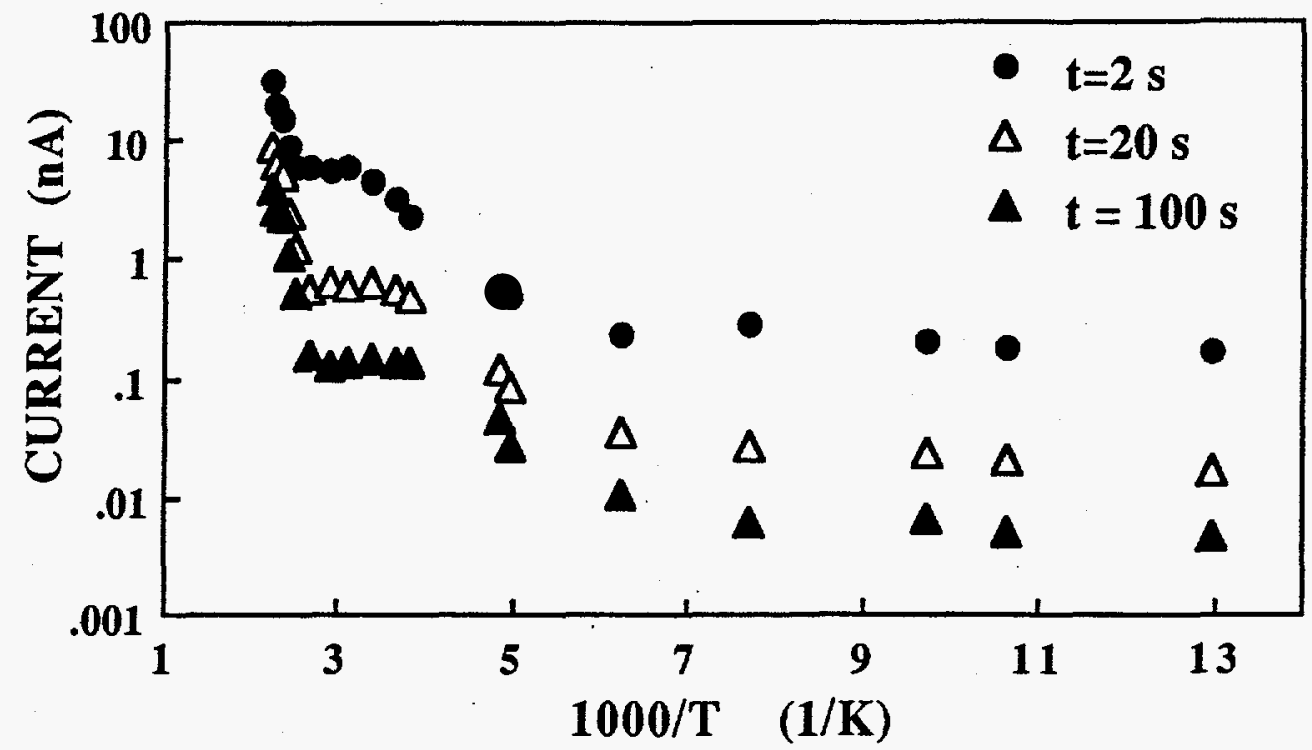

Fig. 3. Arrhenius plots of discharge between $77 \mathrm{~K}$ and $450 \mathrm{~K}$. The region above $300 \mathrm{~K}$ yields a thermal activation energy of $0.66 \mathrm{eV}$.

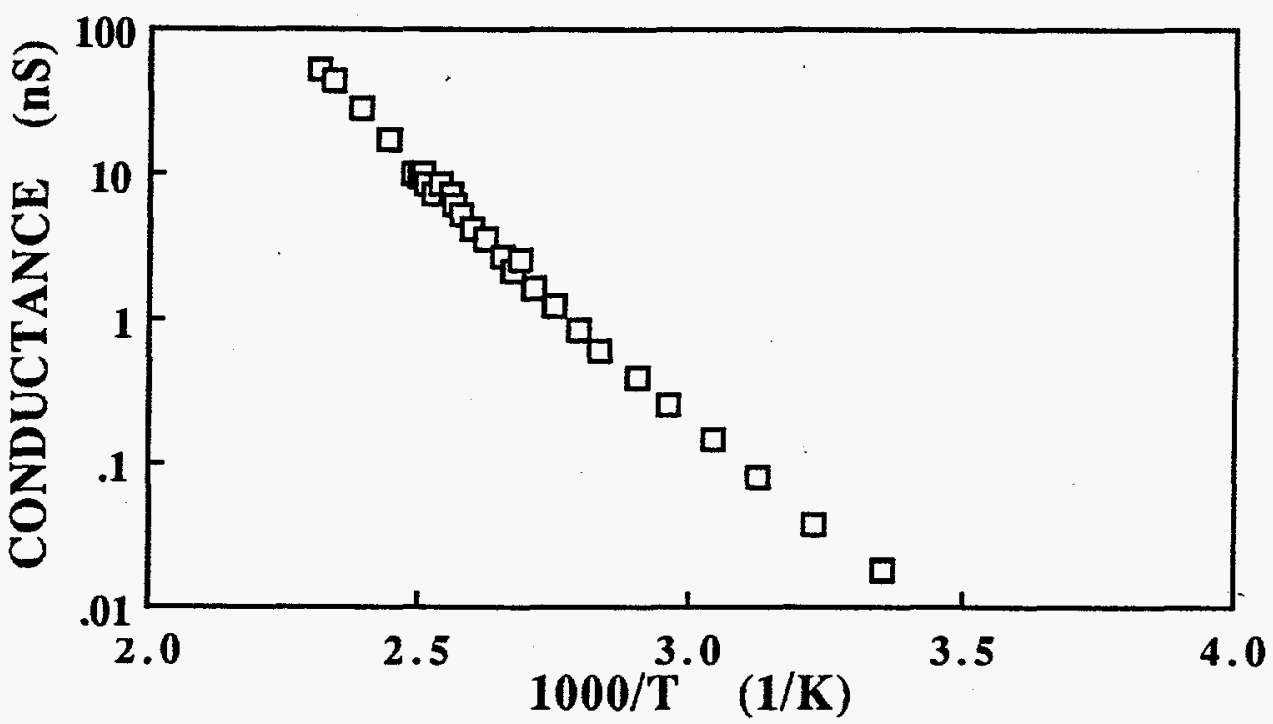

Fig. 4. Conductance at temperatures above 280K. The slope yields $E_{3}=0.68 \mathrm{eV}$. 


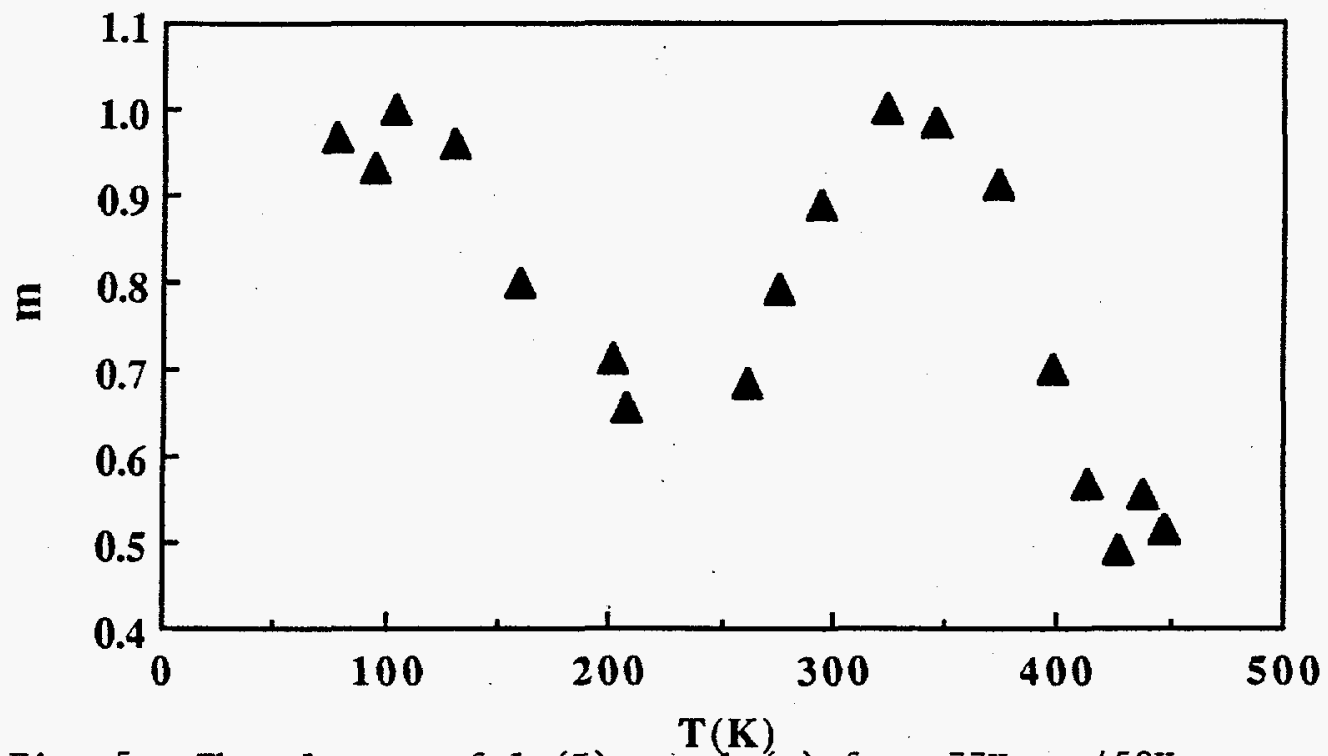

Fig. 5. The slope $m$ of $\ln (\mathrm{I}) \mathrm{vs}$. $\ln (\mathrm{t})$ from $77 \mathrm{~K}$ to $450 \mathrm{~K}$.

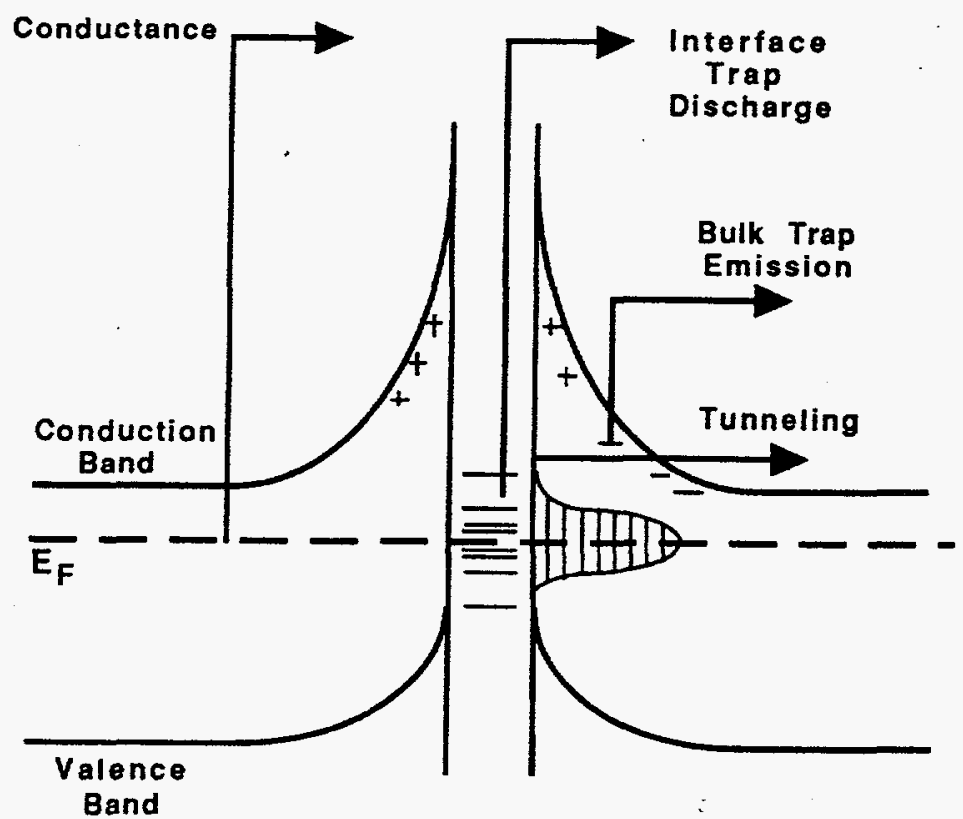

Fig. 6. The shaded area indicates a distribution of interface traps filled to the Fermi Energy $E_{F}$. 